AIDA CHACON • La novela de la Revolución y la novela de la disidencia en la literatura cubana

La novela de la Revolución y la novela de la disidencia en la literatura cubana de los años 70.

The novel of the Revolution and the novel of dissent in Cuban literature of the 70s.

Aida Chacon

Programa de Posgrado en Estudios Latinoamericanos. Universidad Nacional Autónoma.

México.1

\title{
Resumen
}

Desde el triunfo de la Revolución cubana y su posterior institucionalización, la literatura de la isla ha estado en constantes tensiones que han pretendido, a lo largo de los años, dibujar los límites del arte y del compromiso ideológico de los artistas. Sin embargo, durante los años 70, las tensiones llegaron a límites no sospechados y las posturas se polarizaron. Ante el panorama cultural de la isla, algunos escritores determinaron que la única manera de defender el arte era sosteniendo su naturaleza crítica y social desechando la función que el Estado demandaba: hacer del arte un instrumento de difusión ideológica.

En esta primera parte del estudio se sientan las bases de la novela de la Revolución y la novela de la disidencia en Cuba y se establece la clasificación que permitirá el posterior estudio de las poéticas que se alejaron del discurso oficial durante aquella época.

Palabras Claves: Literatura, revolución cubana, Arte, Cultura, Novela

\begin{abstract}
Since the triumph of the Cuban Revolution and its subsequent institutionalization, the literature of the island has been in constant tensions that have sought, over the years, to draw the limits of art and the ideological commitment of artists. However, during the 1970s, tensions reached unsuspected limits and the positions became polarized. Given the cultural landscape of the island, some writers determined that the only way to defend art was to maintain its critical and social nature by rejecting the function that the State demanded: to make art an instrument of ideological diffusion.

In this first part of the study the foundations of the novel of the Revolution and the novel of dissent in Cuba are established and the classification that will allow the subsequent study of the poetics that moved away from the official discourse during that time is established.
\end{abstract}

Key Words: Literature, Cuban Revolution, Art, Culture, Novel

Sabía, como lo sabe cualquier escritor bajo cualquier circunstancia, que la única fórmula para sobrevivir, tanto física como espiritualmente, era escribir.

Reinaldo Arenas.

1 chaconcastellanosa@gmail.com 


\section{Literatura Latinoamericana}

La Revolución cubana tuvo eco y repercusión en muchísimos aspectos; de manera indiscutible, en la literatura y no solamente con respecto a la producción editorial, sino también en la formación misma de una literatura, de corte latinoamericano, alejada de las imitaciones o adecuaciones de los cánones europeos. La nueva literatura latinoamericana tiene su síntesis en Cuba.

Parte de esa formación de lo que se llamó "actual narrativa latinoamericana" tuvo sus cimientos en el debate sobre la función del intelectual y las reflexiones que surgieron en torno a ese concepto. El sociólogo estadounidense Wright Mills puso sobre la mesa de discusión la definición de "intelectual" y señaló que se trataba de un "actor social fundamental y único factor de la transformación en las sociedades pobres y analfabetas del tercer mundo" (Gilman 60). También añadió que si las transformaciones revolucionarias no llegaban a término sería básicamente por culpa de la intelectualidad2. Con esto se estaba formando una nueva relación entre la intelectualidad y la política. ¿Y quiénes eran los intelectuales? ¿A quiénes albergaba esa etiqueta? En realidad, se trataba de una amplia gama de posibles perfiles que abarcaban desde la filosofía hasta la ciencia. Pero no se puede negar el hecho de que la palabra escrita era el principal instrumento del intelectual esto hizo posible que los escritores tuvieran un papel muy importante en la formación de la intelectualidad latinoamericana.

Otro hecho fundamental fue que la intelectualidad también tenía una función social, una misión dentro de la sociedad y el Instituto Cubano del Arte e Industria Cinematográficos (ICAIC) también fue un espacio que debatió desde el cine dicha función. Esta función del intelectual tuvo una importante influencia del pensamiento de Sartre, quien desde mediados de los años cincuenta ya hablaba de la noción de compromiso; este término cimentó la transformación conceptual del escritor en intelectual. Sartre también fue simpatizante de la causa cubana y en las ocasiones en que le preguntaban cómo asumir o ejercer el compromiso contestaba " ¡Vuélvanse cubanos!"(Wright 53). Zygmunt Bauman hace un interesante rastreo sobre el concepto de intelectual, en esa época, señala: "La palabra se aplicaba a una abigarrada colección de novelistas, poetas, artistas, periodistas, científicos y otras figuras públicas que consideraban como su responsabilidad moral y su derecho colectivo intervenir directamente en el sistema político mediante su influencia sobre las mentes de la nación y la configuración de sus dirigentes políticos"3. El compromiso también implicaba una filiación partidista, claramente, inclinada a las izquierdas latinoamericanas. Esta tendencia ya venía haciendo eco desde los años sesenta, cuando Sábato mencionó que los escritores no podían ni debían olvidar la "realidad urgente" que les marcaba "la desdicha y en muchos casos miseria explotación de los países dominados y explotados". (Bauman 9)

Otro elemento importantísimo para la consolidación de la literatura latinoamericana de la época fue la red de revistas político-culturales que ayudó a la consagración tanto de autores como de obras de crucial importancia. En las revistas, los intelectuales (escritores) hallaron un soporte que les permitía asumir su postura política de manera abierta, con alcances masivos y, también, pronunciarse sobre los asuntos contemporáneos y de interés internacional.

${ }_{2}$ Wright, Izquierda, subdesarrollo y guerra fría, pp. 53-69. Conferencia dictada en el COLMEX en el año 1960.

${ }_{3}$ Bauman, Legisladores e intérpretes, p. 9. 
Una institución fundamental en la construcción de la cultura latinoamericana fue la Casa de las Américas; escritores que más tarde serían autores del boom fueron publicados por la revista del mismo nombre. Asimismo, los semanarios Siempre! (México), Primera plana (Buenos Aires), y Marcha (Montevideo) reforzaron la presencia de nuevos intelectuales latinoamericanos y formaron el lugar de enunciación y práctica del compromiso intelectual. Marcha fue una de las publicaciones pioneras que hacía un llamado a la vocación latinoamericanista y que se definía en términos antiimperialistas. El insistente llamado a la unión latinoamericana tuvo eco en más publicaciones como La bufanda del sol (Ecuador) y Amaru (Perú) cuya preocupación fue más allá de las fronteras nacionales pues hacían un llamado a los países de "nuestra lengua" (Gilman 80). Esta línea latinoamericanista fue definida por Casa de las Américas y constatada en cada número de la revista. Su lista de colaboradores cada vez fue más extensa y en la primera edición albergó textos de Antón Arrufat, Virgilio Piñera, Miguel Ángel Asturias y Carlos Fuentes; para el número cinco de la revista se sumaron Juan José Arreola y Elvio Romero. La presencia de críticos y creadores latinoamericanos cada vez fue haciéndose más patente, y se sumaron personalidades como Roque Dalton, Ernesto Sábato, Julio Cortázar, José María Arguedas. Dos años más tarde se incluyeron como miembros del consejo editorial de la revista Julio Cortázar y Emmanuel Carballo. Para el número veinticuatro se incorporaron Ángel Rama y, a partir del número treinta, la revista fue dirigida por Fernández Retamar. La lista de colaboradores fue cada vez mayor, se agregaron trabajos de René Depestre, Lisandro Otero y Graziella Pogolotti, Mario Benedetti, David Viñas y Mario Vargas Llosa. Las relaciones entre las diferentes revistas latinoamericanas también fue una práctica constante y los autores que ya se consolidaban en la literatura tuvieron también presencia en esta red de publicaciones.

Otro factor importante en la consolidación de la literatura latinoamericana fue el posicionamiento de los escritores con respecto a la crítica y el auge de las ediciones que ya eran solicitadas en Europa y Estados Unidos. Para el año 1963 Los albañiles, de Vicente Leñero, ganó el premio Biblioteca Breve de Seix Barral y en 1965 fue una de las novelas más editadas en México; la publicidad de la editorial tuvo un fuerte impacto literario y novelas como La ciudad y los perros, La región más transparente y El llano en llamas, formaban parte de las novelas más publicitadas. Esto tuvo como consecuencia la expansión y crecimiento de las editoriales y se empezó a hablar de la madurez de la literatura hispanoamericana4. Esta aseveración deja manifiesto el hecho de que la publicidad tuvo un papel determinante en la construcción del concepto de literatura latinoamericana, pues ésta no había surgido a partir de los sesenta, sino que más bien fue hasta entonces que logró una red de relaciones suficientes para hacer eco en la literatura mundial.

La publicación de Cien años de soledad (1967) fue la coronación del auge latinoamericano pues ninguna otra obra de la época alcanzó tanta popularidad, aunque se hablaba de Rayuela y Pedro Páramo como las primeras grandes novelas hispanoamericanas.

Los premios literarios de la época también lograron apuntalar la institucionalidad de la literatura latinoamericana en la literatura mundial. Por ejemplo, el premio Nobel otorgado a Miguel Ángel Asturias en 1967 fue el segundo conferido a un latinoamericano; la primera había sido Gabriela Mistral (1945) y después seguiría Pablo Neruda (1971). En 1967 Vargas Llosa ganó el premio Rómulo Gallegos; este mismo galardón también fue otorgado a García Márquez por Cien años de soledad (1972). El premio Seix-Barral (Gilmann 90-92) también contribuyó al reconocimiento de

${ }_{4}$ El 14 de noviembre del 1968 el Times, en su suplemento literario, publicó una nota que sostenía que la contribución más importante a la literatura mundial provenía de América Latina. 
la literatura continental; en 1962 lo obtuvo La ciudad y los perros (Vargas Llosa); en 1963, Los albañiles (Vicente Leñero); 1964, Tres tristes tigres (Guillermo Cabrera Infante); 1967, Cambio de piel (Carlos Fuentes); y en 1968 País portátil (Adriano González León). Otro premio de reconocido prestigio fue el creado por Casa de las Américas.

La producción literaria, así como la fuerte actividad política de los intelectuales en el campo cultural, con énfasis en la literatura, caracterizó a una época que le brindó a latinoamericana una fuerte y decidida presencia en la literatura universal. Su calidad estética y de contenido dio aire nuevo a la crítica europea y nuestra literatura consolidó su identidad más allá de las fronteras regionales.

\section{Novela de la Revolución cubana}

Así como la Revolución cubana representó un parteaguas en la geopolítica de los años sesenta, también lo fue para las artes y la literatura. En palabras de Armando Pereira a partir del triunfo revolucionario en 1959, el escritor cubano comienza a enfrentar su trabajo literario desde parámetros y perspectivas muy diferentes a como lo había estado haciendo hasta entonces. La revolución trae consigo nuevas preocupaciones e intereses para la intelectualidad cubana (Pereira 7). Este nuevo proyecto económico y político también incluyó un nuevo proyecto cultural que ganó la simpatía de muchos intelectuales no solamente de la isla, sino también de Latinoamérica, que se dieron a la tarea de construirlo y fortalecerlo. Intelectuales como Carlos Fuentes, Mario Vargas Llosa, Gabriel García Márquez, Julio Cortázar, Ernesto Cardenal, Jaime Sabines, Mario Benedetti, sólo por mencionar algunos, resultan inseparables de aquella aventura inicial. Es en la década de los años sesenta cuando se desarrolla y profundiza más en las reflexiones teóricas sobre la función social del artista revolucionario. Sobre eso Pereira (8), en su estudio Novela de la Revolución cubana se centra en la producción literaria, novelística, editada dentro de la isla, así como de sus preocupaciones, búsquedas y perspectivas.

La importancia de la literatura en la isla es clara en los inicios del triunfo de la Revolución ya esta le da un impulso enorme a la cultura; en 1960 se funda la Casa de las Américas, a sólo un año se crea la Unión Nacional de Escritores y Artistas Cubanos (UNEAC), aparecen Revistas como Unión, La Gaceta de Cuba y ese mismo año arranca en todo el país una campaña de alfabetización que generará, poco a poco, la demanda de nuevas obras para esos nuevos lectores. En 1962 se crea la Editorial Nacional, dirigida por Alejo Carpentier; más tarde, en 1965, Ediciones Revolucionarias (Panicheli 31) Por lo que será de manera temprana (1961) cuando Fidel Castro pronuncie las "Palabras a los intelectuales" donde dejaba en claro varios conceptos que fueron una llamada de atención para el escritor cubano. En primer lugar, hacía una breve pero certera distinción entre lo que llamó "libertad formal" y "libertad de contenido". La libertad formal no representaba ningún problema, era incluso una muestra de creatividad que sería siempre plausible; nuevas formas gramaticales, nuevos lenguajes, serían necesarios dentro de la experimentación artística. Ninguna libertad de creación será excesiva. Por otra parte, cuando se habló de libertad de contenido, Fidel menciona que "la libertad de contenido sólo puede constituir un problema para el intelectual que no es revolucionario5".

5 Castro, Palabras a los intelectuales, Departamento de versiones taquigráficas: http://www.cuba.cu/gobierno/discursos/1961/esp/f300661e.html 
En este famoso discurso pronunciado por Fidel Castro queda manifiesto de manera contundente que la literatura y el arte han constituido siempre un mecanismo para la manifestación ideológica por lo que el impacto hacia la creación literaria fue relevante. Tan sólo en la década de los sesenta se publicaron casi setenta novelas en la isla (Pereira 7)

Es en ese discurso donde enuncia sus tan famosas palabras que harían eco posteriormente y en diversas ocasiones cuando se trató de frenar a aquellos que no respetaron los parámetros de la "libertad de contenido":

Esto significa que, dentro de la Revolución, todo; contra la Revolución, nada. Contra la Revolución nada, porque la Revolución tiene también sus derechos; y el primer derecho de la Revolución es el derecho a existir. Y frente al derecho de la Revolución de ser y de existir, nadie — por cuanto la Revolución comprende los intereses del pueblo, por cuanto la Revolución significa los intereses de la nación entera-, nadie puede alegar con razón un derecho contra ella6.

Entonces, tenemos claro ya que la novela cubana deberá exaltar los valores de la Revolución que ella misma consagra desde su triunfo:

Los valores que integra la ideología revolucionaria incluyen los del patriotismo, el antiimperialismo, la justicia social, la igualdad, el honor, la dignidad, la honestidad, la disciplina, las normativas jurídicas, las formas socialistas de distribución del producto social, la solidaridad, etc. (Machado 35).

La intelectualidad cubana entonces deberá integrar en su obra literaria los valores que trae consigo la Revolución. Así, cualquier función crítica o de impugnación que tuviera la literatura estará filtrada por el "ser revolucionario" que debe ser cada escritor. Lo que el discurso cultural revolucionario propone es una especie de desplazamiento de esa "conciencia crítica" y de ese "poder de impugnación” del intelectual en las sociedades socialistas (Pereira 19)

Ahora, pues, otra labor titánica será conjugar esos valores con las herramientas con que cuentan los escritores, todos formados e influenciados por tradiciones liberales, tanto latinoamericanas

6 Castro, Palabras a los intelectuales, Departamento de versiones taquigráficas: http://www.cuba.cu/gobierno/discursos/1961/esp/f300661e.html 
como europeas; cambiar categorías del pensamiento liberal como: libertad, individualidad, conciencia crítica, poder de impugnación; por las nuevas categorías nacidas con el triunfo de la Revolución: disciplina, autocrítica, conciencia colectiva y espíritu de partido. (Pereira 19-23)

El estudio de la novela de la Revolución cubana que realiza Armando Pereira comprende desde 1960 hasta 1990. Como está visto, mi propuesta abarca desde finales de los años sesenta hasta la primera década del siglo XXI, por esto mismo es necesario aclarar que ambos estudios se desarrollan impulsados por objetivos similares, sin embargo, el estudio de Pereira se enfoca en trazar las líneas generales de la literatura cubana de esa época y rescata grandes temas discursivos que detalla y ejemplifica con novelas representativas. De otro lado, mi estudio se enfoca en aportar a esa imagen global que Pereira realizó, un enfoque de análisis que responde a la incomodidad que la libertad de contenido causa a más de un intelectual en Cuba: la disidencia.

Entre los intelectuales existió incomodidad por lo que se señalaba como libertad de contenido, quizá debido, en mayor medida, a que "gran parte de los intelectuales en los años 50’s provenían de una clase media urbana que, aunque rechazaban la degradación moral y la corrupción administrativa de Batista, nunca llegaron a participar de una manera activa en las luchas insurrectas" (Pereira 24)

Por cuestiones de espacio no podré abarcar el desarrollo de ambas propuestas, sin embargo, en un apartado posterior mencionaré a los principales representantes de la Novela de la Revolución cubana $\mathrm{y}$, posteriormente, me enfocaré en la definición de disidencia que utilizaré para este estudio.

\section{Novela de la disidencia}

Antes de iniciar el análisis de las obras literarias propuestas es necesario definir puntualmente las de ideología, disidencia y discurso.

La ideología es un concepto clave en este estudio cuya complejidad abarca tanto el campo sociológico como el gnoseológico. A este respecto debo señalar que por cuestiones teóricas me ceñiré a la definición de Luis Villoro sobre este concepto y a continuación lo citaré extensamente:

Se entiende por "ideología" generalmente un marco de creencias y actitudes comunes a un grupo social que ordena las creencias y actitudes de cada individuo perteneciente a ese grupo y le prescribe reglas de comportamiento. Son más resistentes a las innovaciones que los "credos" religiosos o morales y exigen un alto grado de adhesión afectiva. Esas creencias forman un sistema organizado que es aceptado por autoridad y cumple una función de dominio. (Villoro 183) 
También Villoro aclara que no todos los conjuntos de ideas que sean hasta cierto punto irracionales y compartidos por un grupo social, son propiamente ideologías. Por el contrario, para que una ideología pueda ser llamada como tal es necesario que presente dos rasgos más: 1) no se fundan en razones válidas y 2) cumplen la función de promover el poder político de quienes las ostentan. Así, pues, aunque la ideología responde a los intereses de un grupo en el poder, no puede ser impuesta a la fuerza, sino que tiene la misión de "colarse" en el imaginario para ser aceptada o percibida como un interés general. Además de que, como toda ideología, siempre tendrá un discurso justificativo sobre sus principios y su razón de existencia (incluso, su derecho a la existencia, como lo mencionó Fidel Castro en sus "Palabras a los intelectuales"). (Castro 14)

A pesar de las diferentes ideologías que existen, éstas siempre tendrán funciones sociales diversas, a este respecto Terry Eagleton también aporta sus teorizaciones sobre el papel de la ideología. Para el interés concreto de este estudio, la definición de ideología abre la pauta para expresar entonces cuál es o en qué radica o cómo se expresa el concepto propuesto por Eagleton de "disidencia". Debo señalar que a partir de la "ideología" dominante, sin importar si ésta es capitalista o socialista, su objetivo es mantenerse posicionada en el pensamiento de una sociedad o de un determinado grupo para que quienes defiendan sus principios se sientan dentro de una comunidad, partícipes de una colectividad y protegidos y reconocidos por ella. Este rasgo también propicia o es parte de la formación de identidad de un individuo en la colectividad. Por otro lado, una ideología "disidente" pretende llevar a la categoría de interés general la necesidad de un cambio dentro de la ideología imperante. Es por esta razón que los límites entre la literatura y la ideología no se perciben del todo dentro del periodo estudiado y considero de vital importancia estudiarlo como un todo complejo a partir de la política, la sociología y la literatura. Asimismo, propongo la categorización de mi periodo estudiado, con base en características específicas de las obras y sus tópicos que detallaré en el siguiente apartado (Véase: 3.1.3 Una propuesta de clasificación, p. 68) y, partiendo de la aseveración de Tinianov sobre la literatura en relación con las series vecinas, presento un panorama contextual para entender con mayor exactitud la o las formas de representación que la literatura ofrece a sus lectores.

La siguiente cuestión de suma importancia para este análisis es la puntual definición que propongo para el estudio de la literatura cubana, la disidencia. Si bien se trata de una categoría más bien utilizada en política, al ser propuesta como una nueva categoría de análisis literario deberá ser acotada con pertinencia, pues no se trata de una definición única, sin matices o constante en el tiempo.

La disidencia surge cuando el individuo entra en conflicto con las normas establecidas por el poder político imperante. A este respecto considero importante definir previamente algunas categorías que pueden ayudarnos a dilucidar las razones por las cuales el quehacer literario puede resultar una actividad susceptible de ser objeto de la vigilancia del Estado y, por parte del mismo ser, tipificado su contenido como "disidente".

Según Norberto Bobbio y Nicola Matteucci la disensión es un concepto muy amplio y sumamente complejo de definir de manera unívoca. Sin embargo, menciona rasgos concretos:

[...] según la forma que asume, la disensión se concreta en apatía, indiferencia, desapego del sistema político o bien en exhortar, persuadir, criticar, hacer presión con medios violentos o no violentos. (Bobbio 506.) 
Estos teóricos también señalan que la disensión puede ser individual o colectiva y que los protagonistas son de orígenes sociales distintos, con diversos perfiles, desde artistas, intelectuales, escritores, hasta obreros y campesinos. Asimismo, aclaran que la disensión es un fenómeno que es tolerado e incluso hasta protegido dentro de los regímenes democráticos, mientras que en sociedades que no son de carácter democrático sus implicaciones son distintas:

En la amplia gama de los regímenes no democráticos, desde los tradicionales hasta los autoritarios o totalitarios, las manifestaciones de la disensión son limitadas en una medida mayor o menor. En todo caso la disensión no está protegida. La autoridad política la siente como una amenaza muy grave a su poder, incluso debido a que existe la posibilidad concreta de que la disensión contribuya al aglutinamiento de todos los opositores al régimen [...]. En consecuencia, las sanciones contra los disidentes son mucho más duras, incluso porque se les reconoce justamente como culpable de actividades antiestatales. (Bobbio 509)

La siguiente categoría a definir en este estudio es el discurso. Si bien los estudios culturales han problematizado sobre la naturaleza social del lenguaje, es necesario tomar en cuenta que el lenguaje cumple una función mediadora en la representación de "lo real". Mónica Szurmuk y Robert McKee lo definen de la siguiente manera:

Discurso (con mayúscula) implica una práctica social que rebasa la expresión lingüística e incluye sistemas de creencias y formas de pensar, actuar e interactuar (Gee, 1999). [...] hace referencia a sistemas de representación que regulan lo que se puede hacer con el lenguaje en una situación y contexto determinados. [...] Para Foucault (1970), el discurso constituye mucho más que el soporte lingüístico de la ejecución verbal, ya que establece los límites del comportamiento lingüístico según el momento histórico en el que se sitúa; es decir, esta noción de discurso hace referencia a lo que puede o no puede ser dicho en una formación discursiva 
AIDA CHACON • La novela de la Revolución y la novela de la disidencia en la literatura cubana

específica. Una formación discursiva, según Foucault, es el conjunto de reglas que en un determinado momento histórico regula y determina las modalidades enunciativas, la formación de conceptos, las estrategias posibles, y la formación de los objetos. (Skurmuk 89)

Al dejar claro que el discurso, como práctica social, se trata de un agente estructurante en la construcción de la realidad, considero pertinente explicar las series propuestas por Tinianov donde propone que:

La obra [literaria] establece numerosas correlaciones que alimentan una constante influencia recíproca, por la cual los fenómenos literarios no pueden considerarse jamás como fuera de tales correlaciones con las series vecinas, es decir, con la vida social; correlaciones que se establecen a través de la actividad lingüística. La literatura aporta significados a la cultura, le ayuda a expresar y a recrear sus valores, sin que el universo de la literatura y la cultura sean el mismo universo.

En esta correlación de proximidades podemos identificar entonces que la serie cultural influirá a la serie literaria en cuanto a los valores, los hábitos, ideas, expresiones y visión del mundo en que el autor está inserto. El arte, en este caso la literatura, se convierte en una interpretación de la realidad cultural e histórica que acontece en un momento y lugar determinados. ¿Cómo la literatura puede representar una amenaza al régimen establecido? Para contestar esta pregunta recurriré a las palabras de Eagleton "El texto literario no es la expresión de la ideología, ni la ideología es la "expresión" de la clase social. El texto literario resulta más bien, una especie de producción ideológica, para la cual, en ocasiones, puede ser válida la analogía con una producción dramática.”. (599)

A partir de esta aseveración tenemos más elementos para entender cómo la literatura está permeada por el discurso social y puede crear ideología, en este caso, contraria a un régimen político y por esta causa ser, como en el caso cubano, sometida a un escrutinio exacerbado. Sin embargo, debo acotar que el texto literario no es un reflejo de la realidad o un medio para transmitir ideología, por el contrario, dice Eagleton, en el texto literario se encuentra presente una doble ausencia de la realidad histórica: el texto toma como objeto no a la realidad, pero sí a ciertos significados por los cuales lo real cobra vida y estos significados son a su vez el resultado de su abolición parcial. (Beristain 458) 
El lenguaje y el pensamiento están íntimamente ligados al quehacer filosófico que conlleva al ser humano a la búsqueda de la libertad, bien lo dijo Arenas en Antes que anochezca, "grito, luego existo" (Arenas 322). No se puede aplacar el pensamiento ni evitar su cauce y el de la palabra, pero por ello tiempo, la palabra, la retórica, la literatura, la propaganda, la información, es decir, construcciones discursivas, serán las formas más eficaces para usar elementos profundamente incrustados en la cultura social y abrir, como en el caso que abordamos, la caja de Pandora de la violencia política. El discurso escrito (como juego de dominación), usado para llevar a cabo la violencia, será el factor que unirá a los principios morales, las creencias de una sociedad con los intereses que necesitan llevar a cabo actos de violencia política. (Eagleton 559)

A este respecto Mario Magallón señala que:

La ideología y la política comparten dos características principales: una representación de la sociedad y un programa político. La imagen que ofrecen es la de una sociedad inteligible, pero vista desde un ángulo particular. Porque se acentúan y contrastan diferentes aspectos del mundo social, con el fin de ilustrar cómo actúa la realidad en su conjunto y también cómo se debería organizar desde el enfoque idealizado, mismo que transmite un programa de acción, como aquel que contempla qué recomendaciones deben hacerse para garantizar la debida convergencia entre el ideal y la realidad social. [...] Por el contrario cuando la realidad y el ideal se configuran de acuerdo a aspectos básicamente incongruentes, las recomendaciones tienen un carácter más práctico, incluidos el corte sin paliativos con el fin de reconstruir el orden político. (Magallón 174)

A partir de la restitución del orden político al precio necesario, la violencia de Estado se hace manifiesta con el fin único de "proteger" a la sociedad de sí misma.

Por esta misma causa sitúo el parteaguas de mi investigación en el Caso Padilla; es a partir de este acontecimiento que planteo mi categoría disidente en el tiempo de la realidad social en Cuba del siglo XX.

La disidencia literaria no es, ni puede serlo nunca, la misma a lo largo de mucho tiempo. La razón es que las políticas culturales cambian, los tiempos cambian, la realidad cotidiana cambia y el discurso social que permea al discurso literario también lo hace. Es por eso que propongo que el tratamiento de esta categoría se haga a partir de la segmentación en décadas y, como mencioné en la introducción de este estudio, es necesaria esta segmentación para abordar el análisis literario de 
una forma práctica que permita conocer ciertas complejidades que se encuentran cercanas en la historia y que posibilitan la apreciación del objeto de estudio como una unidad. También debo señalar que esta partición por décadas es en todos los casos arbitraria, pues los acontecimientos no inician y terminan a la par del periodo de tiempo en cuestión, sino que se continúan y presentan paulatinamente algunos rasgos o intensidades que los definen o caracterizan.

También es de suma importancia analizar por qué la literatura es tan vigilada, no sólo por tratarse de un medio para difundir ideología, sino también porque se trata de una praxis del lenguaje humano que posibilita una resignificación de la realidad interpretada por diferentes formas. Es decir, en palabras de Jorge A. González: "La religión, la moral, la educación, la cultura, el arte, en fin, la ciencia, son complejos metalenguajes elementales humanos." (González 6) Gracias a estos metalenguajes desarrollamos también la capacidad reflexiva. He aquí una gran revelación sobre la literatura: a través de la lectura podemos entonces reflexionar sobre la realidad, en el caso de mi estudio puede tratarse de una realidad reconfigurada con el paso del tiempo. También, por esta misma razón, es necesario acotar que la disidencia no puede ser entendida de la misma manera en todo momento, pues la realidad no es una y absoluta, sino que se transforma en el momento en que cada ser humano la interpreta, y esta interpretación puede variar dependiendo del momento, el lugar, el momento personal de quien la interpreta, el contexto en el que se está (González 4)

Hablar de una literatura de la disidencia implica ya, de principio, catalogar un tipo de literatura que quizá sólo ha cumplido con la función de todo ser humano, la observación y la interpretación, binomio que no puede ser separado pues no es posible ver los objetos o situaciones de la "realidad" como algo "puro", sólo podemos concebirlos a través de nuestros filtros, de nuestro lenguaje y los metalenguajes derivados (González 19)

Estos mismos metalenguajes pueden ser también códigos "cifrados", es decir, se requiere de un marco epistémico determinado para poder acceder al conocimiento o la porción de realidad que se presenta discretamente a través de la literatura; entre más nutrido sea este marco epistémico, seremos capaces de hacer mayores relaciones entre diferentes objetos y representaciones. Es por esta misma razón que obras como Fuera juego, de Heberto Padilla, tienen peligrosas interpretaciones de una realidad que pueden afectar la percepción colectiva de un sistema instaurado en Cuba a principios de los años sesenta; por ejemplo, en el poema titulado Poética, Padilla hace una invitación a una literatura comprometida que denuncie, de alguna manera, los abusos de ciertos miembros del poder:

Di la verdad.

Di, al menos, tu verdad.

Y después

deja que cualquier cosa ocurra:

que te rompan la página querida,

que te tumben a pedradas la puerta, 
que la gente

se amontone delante de tu cuerpo

como si fueras

un prodigio o un muerto. (Padilla 33)

Sin embargo, la peligrosidad de esta invitación radica en la facilidad con que el lector puede relacionar la realidad de un sitio distante en la tierra, pero más que cercano en ideología y en el aparato de Estado.

Ahora, pues, partiendo del hecho de que la literatura puede ser un vehículo ideologizante, las políticas culturales y la censura en Cuba han sido determinantes en la historia de su literatura, por esta misma razón no podría abordar un estudio serio de la producción literaria en la isla sin tomar en cuenta factores que pertenecen a otras disciplinas que están más allá de la literatura. La misma censura, la persecución de intelectuales y artistas cubanos, el exilio, la diáspora son fenómenos que van más allá de un hecho testimonial, son cuestiones políticas que se han ido permeando en distintos aspectos de la vida en la isla y, claro está, permearán el discurso social y con ello las diversas manifestaciones artísticas. La literatura, el lenguaje y el discurso narrativo se tornan, en tiempos de resistencia, en un ejercicio de libertad o en vehículo para la liberación.

Recapitulando, después de conocer el contexto histórico y cultural cubano de la época que se aborda, para este estudio quiero proponer elementos que pueden traducirse o verse como una ruptura epistemológica que permita reinterpretar la disidencia, para entender la categoría literatura de la disidencia como una oposición directa o indirecta al régimen político, y también como una manifestación discursiva y crítica que no reconoce fronteras geográficas debido a que su génesis está dentro de la isla de Cuba; y para la correcta historiografía y estudio de la literatura cubana no se puede estudiar de manera separada la literatura dentro de la isla y fuera de ella, porque ambas conforman la totalidad de la literatura cubana.

\section{Proyecciones.}

Creo que reflexionar en torno a esta literatura abre la posibilidad de plantear nuevas preguntas de investigación para atender viejos problemas que surgieron entonces en torno a la literatura y las artes como ¿Debe existir un compromiso del artista? ¿Cuáles fueron los límites de la inclusión del Estado en los sectores culturales? ¿Qué hay detrás del discurso literario?

Ahora bien, el Caso Padilla es el punto de inflexión en el que la intelectualidad cubana y el régimen de Castro rompen relaciones de una manera dramática. Fue un hecho que marcó un antes y un después para la literatura y las artes, no solamente en Cuba sino en toda América Latina. Intelectuales de la talla de García Márquez, Julio Cortázar, Jean-Paul Sartre y Simone de Beauvoir tomaron partido ante este hecho histórico, por su parte, Goytisolo también manifiesta su desilusión sobre la Revolución cubana (Camacho 156). 
Posteriormente al arranque de la literatura de la disidencia7 se encuentra la primera década de estudio que comprende, a manera de contextualización, desde finales de los años sesenta, y como análisis de la producción creativa desde 1971 hasta 1981. Este es un periodo de tiempo que no tiene límites establecidos con calendario en mano sino emparejado con los acontecimientos sociales, políticos y culturales que sucedieron en esos años: El caso Padilla (1971) y el éxodo del Mariel (1981).

\section{Una propuesta de clasificación}

Con la Revolución llegó un reordenamiento axiológico y el debate toca una problemática sumamente compleja: cuáles eran los significados extraliterarios que debían ser abordados desde la literatura y cómo lograr esa labor tan clara en el discurso, pero difusa en la práctica. Alberto Garrandés opina que:

A fines de los años 60 la política cultural cubana se encargó, indirectamente, de dirimir la querella de la prosa realista con la prosa imaginativa [... y tuvo lugar una especie de confrontación dualista en favor del realismo social. Un realismo utopista, complaciente y que tenía la misión de redramatizar la historia y desdramatizar la inmediatez, envuelta entonces en un epos denso y suficiente. La narrativa de la imaginación no desapareció, pero sí empezó a avanzar por un sendero accidentado, periférico, situado en las afueras del campo intelectual deseable". (Garrandés 182)

Considero pertinente mencionar que debido a esta segregación literaria he decido enfocar mi análisis en un corpus cuya publicación no se llevó a cabo dentro de la isla (o sí, pero de manera discreta) y que, además, el lugar otorgado por la crítica le ha restado importancia literaria y, hasta cierto punto, desdeñado la obra por la vorágine personal que acompañó a más de un autor.

Con esta primera propuesta de segmentación me daré a la tarea de seleccionar y analizar un corpus representativo que muestre ejemplos claros sobre las categorías propuestas, mismas que estarán detalladas a continuación.

La literatura de la disidencia estará tipificada de la siguiente forma:

a) Obras publicadas fuera de la isla y prohibidas dentro de la misma, ya sea por su contenido o cualquier otra circunstancia.

b) Obras que critican -explícita o implícitamente- los valores de la Revolución.

c) Obras que enaltecen valores del capitalismo.

d) Obras que critican -explícita o implícitamente- al régimen político, sus gobiernos, sus servidores.

${ }_{7}$ Probablemente esta categoría pueda abarcar aún más allá de la primera década del siglo XXI, pero por cuestiones de tiempo esta investigación se tendrá que ceñir a una segmentación del estudio, mismo que podrá servir para futuras investigaciones. 
e) Preponderancia de personajes disidentes.

f) Temáticas comunes: voz, silencio y censura.

g) Recepción positiva o negativa de la obra.

Es importante destacar que la recepción de la obra también brinda un sesgo importante para el estudio de la literatura, debido a que no todo será siempre catalogado como disidente desde el primer conocimiento público de la obra. Cabe recordar tan sólo el poemario de Heberto Padilla que fue premiado por la UNEAC, mismo que habría de costarle encierro en prisión, tortura y retractación a Padilla tan sólo unos años después.

A partir de esta clasificación, posteriormente en un segundo ensayo realizaré un análisis breve de tres obras que fueron censuradas de diversas formas dentro de la isla y cuyas posturas de sus autores también fueron abiertamente contrarias al Estado: Arturo, la estrella más brillante (1971), de Reinaldo Arenas; Vista del amanecer en el trópico (1974), de Guillermo Cabrera Infante y En mi jardín pastan los héroes (1981) de Heberto Padilla.

\section{Bibliografía}


AIDA CHACON • La novela de la Revolución y la novela de la disidencia en la literatura cubana

Arenas, Reinaldo (2012). Necesidad de libertad. Sevilla: Point de lunettes, 2012. Impreso

Arturo, la estrella más brillante, Barcelona: Montesinos, 1984. Impreso

Bauman, Zygmunt. Legisladores e intérpretes, Buenos Aires: Universidad Nacional de Quilmes, 2010.Impreso.

Beristaín, Helena. Diccionario de retórica y poética. 9a edición, México: Porrúa, 1995. Impreso.

Análisis estructural del relato literario, México: UNAM-Limusa, 2013. Impreso.

Bobbio, Norberto. Matteucci, Nicola. Diccionario de Política. 13a edición, México: Siglo XXI, 2012. Impreso.

Borja, Rodrigo. Enciclopedia de la Política. Tomo I. México: FCE, 2012. Impreso.

Camacho, Enrique. Pueblo en marcha, cincuenta años después. Juan Goytisolo y la Revolución cubana. En: Vanden Berghe, Kristine. El retorno de los galeones. Literatura, arte, cultura popular, historia. Bélgica :Trans-Atlántico. pp. 151-169, 2011. Impreso.

Castro, Fidel. Palabras a los intelectuales, Departamento de versiones taquigráficas: www.cuba.cu: discursos, 2016. Impreso.

Eagleton, Terry. "Hacia la ciencia del texto" en Textos de teorías y crítica literaria, México: UAM, pp. 559-565, 2016. Impreso.

Garrandés, Alberto. Presunciones, La Habana: Letras cubanas, 2005. Impreso.

Gilman, Claudia. Entre la pluma y el fusil. Debates y dilemas del escritor revolucionario en América Latina. 2da. edición, Argentina: Siglo XXI, 2012. Impreso.

González, Jorge. Cibercultura e iniciación en la investigación. México: CONACULTA-UNAMCAIICH-Instituto Mexiquense de Cultura, 2007. Impreso.

Machado Rodríguez, Darío L. Problemas del papel de la ideología en la transición socialista cubana, pp. 35, consultado en http://info.nodo50.org/.Web . 15 Nov. 2013.

Magallón Anaya, Mario. Discurso filosófico y conflicto social en América Latina. México, CIALC- UNAM, 2007. Impreso.

Moreno Soto, Juan Ernesto. El horror no cesa: memorias y testimonios de la violencia política en el Perú contemporáneo, UNAM. México, 2012. Impreso.

Padilla, Heberto. Fuera del juego. Versión comentada por Manuel Díaz. Círculo de poesía. 2010. Impreso.

Panichelli Teyssen, Stéphanie. La Pentagonía de Reinaldo Arenas: un conjunto de novelas testimoniales y autobiográficas, Universidad de Granada, Departamento de Filología española: Tesis doctoral. Granada, 2005. Impreso.

Pereira, Armando. Novela de la Revolución cubana (1960-1990). México: IIF-UNAM, 1985. Impreso.

Sabato, Ernesto. Sobre un congreso. Revista Clarín, 14 de febrero,1960. Impreso.

Tinianov, J. "La noción de construcción" en: Tzvetan Todorov. Teoría de la literatura de los formalistas rusos, 3ra edición, México: XXI Editores, 1978. Impreso.

Villoro, Luis. El poder y el valor. Fundamentos de una ética política, México: FCE, 2000. Impreso.

Wright Mills, C. "Izquierda, subdesarrollo y guerra fría. Un coloquio sobre cuestiones fundamentales", Cuadernos americanos, no. 3, mayo-junio, pp. 53-69. 1960. Impreso.

Recibido: 26 de Diciembre de 2019

Aceptado: 30 de Diciembre de 2019 